\title{
Los enemigos que amenazan la efectividad real de los planes de igualdad*
}

\author{
The enemies that threaten the real effectiveness \\ of equality plans
}

\author{
CARMEn Grau Pineda* \\ Profesora Titular de Derecho del Trabajo y de la SS \\ Universidad de Las Palmas de Gran Canaria (ULPGC) \\ ORCID: 000-0003-0274-8875
}

Recibido: $15 / 01 / 2020$

Aceptado: 01/03/2020

doi: https://doi.org/10.20318/femeris.2020.5382

Resumen. Hace más de una década que se aprobó la Ley Orgánica 3/2007 para la igualdad efectiva de mujeres y hombres, conocida como la Ley de Igualdad, y parece un tiempo suficiente para hacer balance del grado de efectividad que ha tenido a lo largo de estos años el instrumento concreto por ella impulsado para corregir la desigualdad entre mujeres y hombres en las empresas: los planes de igualdad. Transcurrido este tiempo, se antoja un ejercicio no solo interesante sino necesario analizar sus aspectos jurídicos más controvertidos, aspectos fundamentalmente referidos a sus problemas de efectividad o eficacia real. Análisis crítico que siempre interesa llevar a cabo en aras de poner de manifiesto los éxitos y fracasos, las fortalezas y debilidades, de cara a plantear las modificaciones necesarias para seguir avanzando en el objetivo genético de los planes de igualdad. Son diversos y variados los enemigos que se ciernen sobre su efectividad real pero ha decidido dedicarse la atención a los tres más recurrentes: un diagnóstico incorrecto, una comisión de control y seguimiento ineficaz y un contenido apropiado para alcanzar el fin perseguido.

Palabras clave: igualdad, Ley de Igualdad, planes de igualdad, diagnóstico, control y seguimiento.

Abstract. It was more than a decade ago since it was approved the Organic Law 3/2007 for the effective equality of women and men, known as the Law of Equality, and it seems sufficient time to take stock of the degree of effectiveness that it has had throughout these years the concrete instrument promoted by her to correct inequality between women and men in business: equality plans. After this time, it seems like an exercise not only interesting but necessary to analyze its most controversial legal aspects, aspects fundamentally referred to its problems of effectiveness or real effectiveness. Critical analysis that always interests to carry out in order to show the successes and failures, the strengths and weaknesses, in order to pro-

\footnotetext{
"Premio "8 de marzo - Igualdad de las mujeres" 2020 de la AEDTSS. Al haber sido objeto de evaluación y merecedor del premio, este trabajo queda eximido de la evaluación anónima prevista en Femeris.

${ }^{* *}$ carmen.grau@ulpgc.es
} 
pose the necessary modifications to continue advancing in the genetic objective of the equality plans. There are diverse and varied enemies that hover over their real effectiveness but has decided to devote attention to the three most recurrent: an incorrect diagnosis, an ineffective monitoring and control commission and appropriate content to achieve the desired goal.

Keywords: equality, Equality Act, equality plans, diagnosis, control and monitoring.

\section{Algunas consideraciones preliminares sobre la igualdad y la contribución de la negociación colectiva, a través de los planes de igualdad, a su consecución plena}

Después de todo lo que se ha escrito sobre los planes de igualdad (en adelante, PI) desde su aparición hace ya más de una década (trece años en marzo del año en curso), se antoja un ejercicio no solo interesante sino necesario analizar sus aspectos jurídicos más controvertidos, aspectos fundamentalmente referidos a sus problemas de efectividad o eficacia real. Análisis crítico que siempre interesa llevar a cabo en aras de poner de manifiesto los éxitos y fracasos, las fortalezas y debilidades, de cara a plantear las modificaciones necesarias para seguir avanzando en el objetivo genético de los planes de igualdad.

Pero conviene comenzar por sentar algunas bases. En primer lugar, la Ley Orgánica 3/2007, de 22 de marzo, para la igualdad efectiva de mujeres y hombres (en adelante LOI), toma como punto de partida, como no podía ser de otro modo, tanto el artículo 14 de la Constitución española que proclama el derecho a la igualdad y a la no discriminación por razón de sexo como el artículo 9.2 que consagra la obligación de los poderes públicos de promover las condiciones para que la igualdad del individuo y de los grupos en que se integra sean reales y efectivas. La igualdad entre mujeres y hombres es un principio jurídico universal reconocido en diversos textos internacionales sobre derechos humanos -entre los que destaca la Convención sobre la eliminación de todas las formas de discriminación contra la mujer, aprobada por la Asamblea General de Naciones Unidas en diciembre de 1979 y ratificada por España en $1983^{1}$-, pero también es un principio fundamental en la Unión Europea ${ }^{2}$ desde la entrada en vigor del Tratado de Ámsterdam, el 1 de mayo de

\footnotetext{
${ }^{1}$ La Convención sobre la eliminación de todas las formas de discriminación contra la mujer (CEDAW) representa un instrumento de carácter internacional que incorpora una perspectiva de género y pone de manifiesto en el ámbito jurídico internacional las diversas formas de discriminación contra las mujeres. Se trata del primer instrumento internacional que amplía la responsabilidad estatal a actos que cometen personas privadas, empresas o instituciones no estatales u organizaciones no gubernamentales. Al pretender eliminar la discriminación de iure y de facto, pretende lograr no sólo la igualdad de iure, sino la igualdad de facto o igualdad real o sustantiva. El objetivo es la transformación social, el cambio social que va más allá del cambio legislativo, aunque lo incluye. Es más, la igualdad de iure se concibe sólo como un medio para lograr la realización práctica del principio de igualdad. Tampoco la igualdad de iure se concibe como un tratamiento exacto por parte de la legislación a hombres y mujeres. Se trata de una igualdad basada en el goce y el ejercicio de los derechos humanos que, por lo tanto, permite trato distinto, aún por parte de la ley, cuando la situación es distinta. La CEDAW instaura el concepto de igualdad sustantiva, conformada por la interacción de dos principios contenidos en la misma convención: 1. El principio de no discriminación (art 1 CEDAW) y 2. El principio de la intervención o responsabilidad estatal (arts. 2 a 16). Más detalles al respecto en GARRIDO JIMÉNEZ, LORENA: “Los planes de igualdad en las empresas y su desarrollo en momentos de crisis", http://vlex.com/vid/planes-igualdad-empresas-momentoscrisis-339347262, pp. 375-376 de la versión electrónica.

${ }^{2}$ En particular, esta Ley incorpora al ordenamiento español dos directivas en materia de igualdad de trato, la 2002/73/CE, de reforma de la Directiva 76/207/CEE, relativa a la aplicación del principio de igualdad de trato entre hombres y mujeres en lo que se refiere al acceso al empleo, a la formación y a la promoción profesionales, y a las condiciones de trabajo; y la Directiva 2004/113/CE, sobre aplicación del principio de igualdad de trato entre hombres y mujeres en el acceso a bienes y servicios y su suministro.
} 
1999 en el que la igualdad entre mujeres y hombres y la eliminación de las desigualdades entre unas y otros son un objetivo que debe integrarse en todas las políticas y acciones de la Unión y de sus miembros.

Sin embargo, y ya en segundo lugar, reconoce la LOI, que el pleno reconocimiento de la igualdad formal ante la ley, aun habiendo comportado, sin duda, un paso decisivo, ha resultado ser insuficiente. Y se explaya en relatar que "la violencia de género, la discriminación salarial, la discriminación en las pensiones de viudedad, el mayor desempleo femenino, la todavía escasa presencia de las mujeres en puestos de responsabilidad política, social, cultural y económica, o los problemas de conciliación entre la vida personal, laboral y familiar muestran cómo la igualdad plena, efectiva, entre mujeres y hombres (...) es todavía hoy una tarea pendiente que precisa de nuevos instrumentos jurídicos" (E.M. LOI, II). En definitiva, concluye que resulta del todo necesaria, una acción normativa dirigida a combatir todas las manifestaciones aún subsistentes de discriminación, directa o indirecta, por razón de sexo y a promover la igualdad real entre mujeres y hombres, con la remoción de los obstáculos y estereotipos sociales que impiden alcanzarla que, de otro lado, es ineludible por derivar de nuestro ordenamiento constitucional.

En tercer lugar, deriva, además, de la LOI la transversalidad del principio de igualdad de trato y oportunidades entre mujeres y hombres, esto es, que haya de informar, con carácter transversal, la actuación de todos los poderes públicos (mainstreaming ex art. 15). Y, para ello, la LOI pretende "el establecimiento de criterios de actuación de todos los poderes públicos en los que se integra activamente, de un modo expreso y operativo, dicho principio; y con carácter específico o sectorial, se incorporan también pautas favorecedoras de la igualdad en políticas como la educativa, la sanitaria, la artística y cultural, de la sociedad de la información, de desarrollo rural o de vivienda, deporte, cultura, ordenación del territorio o de cooperación internacional para el desarrollo" (E.M. LOI, III). La transversalidad instaurada por la LOI persigue la "penetración de este principio en todos los ámbitos del sistema social, entre los que se encuentra el laboral, siendo una de sus novedades más destacadas, en relación con la negociación colectiva, la regulación de los planes de igualdad, los cuales han constituido la medida que ha cobrado más protagonismo en la lucha por la igualdad efectiva de mujeres y hombres en el campo laboral"'. Y es que, la LOI presta especial atención a la "corrección de la desigualdad en el ámbito específico de las relaciones laborales [y para ello y] mediante una serie de previsiones, se reconoce el derecho a la conciliación de la vida personal, familiar y laboral y se fomenta una mayor corresponsabilidad entre mujeres y hombres en la asunción de obligaciones familiares, criterios inspiradores de toda la norma que encuentran aquí su concreción más significativa”. La LOI pretende, particularmente, promover la adopción de medidas concretas en favor de la igualdad en las empresas, situándolas en el marco de la negociación colectiva, para que sean las partes, libre y responsablemente, las que acuerden su contenido (E.M. LOI, III). Como acertadamente se ha señalado "planteado de este modo, resulta evidente

\footnotetext{
${ }^{3}$ MONEREO PÉREZ, JOSÉ LUIS Y GUINDO MORALES, SARA: “Planes de igualdad”, en SÁNCHEZ TRIGUEROS, C. (Dir.): Un decenio de jurisprudencia laboral sobre la Ley de igualdad entre mujeres y hombres, BOE, 2018, p. 567.
} 
que la negociación colectiva puede actuar como fuerza motriz en la lucha contra la discriminación por razón de género ${ }^{4 \prime}$.

En cuarto lugar, será a partir de este momento, cuando la igualdad de oportunidades y la no discriminación por razón de sexo en el marco de las organizaciones laborales pasara a convertirse "en una viga maestra de la gestión empresarial, fomentada por la aprobación de tal conjunto normativo específico sobre la materia". De la LOI dijo que "revolucionó el sistema de relaciones laborales en España y [que] se ha consolidado como un hito legislativo en materia de igualdad ${ }^{6 \prime}$. La incorporación de la igualdad de género en las empresas pasó a ser entonces materia obligatoria de la negociación colectiva (arts. 45-48 LOI), corrigiendo así la desigualdad en el ámbito específico de las relaciones laborales y asignando un rol especial a la misma, el papel protagonista o principal que diríamos. Pero repárese en cómo la LOI pretende promover la adopción de medidas concretas a favor de la igualdad en las empresas, situándolas en el marco de la negociación colectiva, para que sean las partes, libre y responsablemente, las que acuerden su contenido y sin casi ningún tipo de imperativo legal (más allá de los supuestos en que es obligatorio negociarlos). La LOI contempla diversas medidas en este sentido, siendo la más relevante, mayoritariamente en la doctrina iuslaboralista, el que se negocien por los agentes sociales en el convenio medidas garantes de la igualdad real entre mujeres y hombres, en general, y, más concretamente, planes de igualdad.

$Y$ es que, considerada la negociación colectiva como el espacio natural del ejercicio de la autonomía colectiva de las organizaciones empresariales y sindicales y el ámbito apropiado para facilitar la capacidad de adaptación de las empresas, fijar las condiciones de trabajo y modelos que permitan mejorar la productividad, crear más riqueza, aumentar el empleo, mejorar su calidad y contribuir a la cohesión social, se la configura como el espacio natural para que este tipo de preocupaciones encuentre respuesta. De hecho, el IV Acuerdo para el Empleo y la Negociación Colectiva (2018-2020) incorpora un anexo en el que se reflejan "Acuerdos alcanzados en el ámbito bipartito que deben ser desarrollados en el ámbito tripartito con el Gobierno de España" y que incluye el mandato a las partes firmantes del mismo de desarrollar medidas integrales para favorecer la igualdad laboral y salarial entre hombre y mujeres ${ }^{7}$. Conviene recordar que el objetivo de estos acuerdos

${ }^{4}$ FERNÁNDEZ-PEINADO MARTÍNEZ, ALICIA Y BASTERRA HERNÁNDEZ, MIGUEL: "Principales actuaciones en materia de no discriminación por razón de sexo en las empresas con el distintivo "igualdad en la empresa". Puntos críticos y propuestas de mejora", Revista Internacional y Comparada de Relaciones Laborales y Derecho del Empleo, Vol. 7, no 3, 2019, p. 31.

${ }^{5}$ MENÉNDEZ CALVO, REMEDIOS: “Impacto laboral de la implementación de planes y políticas de igualdad en las empresas", Anuario de la Facultad de Derecho de la Universidad de Alcalá, IV, 2011, p. 168.

${ }^{6}$ Ídem, p. 170.

${ }^{7}$ Que contemplen, al menos, los tres siguientes:

- Un desarrollo del sistema de atención a la dependencia y la infancia que dé la cobertura necesaria para que la actividad profesional retribuida de las mujeres en las empresas no se vea tan afectada como en la actualidad por estas contingencias.

- Una equiparación en las condiciones de disfrute de los permisos de paternidad/maternidad o de las reducciones de jornada, de manera que se incentive desde el poder público que hombres y mujeres se acojan al ejercicio del derecho de forma equitativa, igualitaria e intransferible.

- Un estudio cualitativo del sistema de pluses y complementos salariales, midiendo su impacto de género y que informe adecuadamente a las comisiones negociadoras de los convenios colectivos, para la adaptación de éstos a criterios que no conlleven un impacto de género. 
no es otro que orientar la negociación de los convenios colectivos durante la vigencia de éste, estableciendo criterios y recomendaciones para acometer en los procesos de negociación colectiva ${ }^{8}$.

En quinto y último lugar, los PI aparecen definidos y configurados de forma no solo amplia sino flexible, dado que permite una gran capacidad de gestión y organización a las partes negociadoras que intervienen en la puesta en marcha del proceso de negociación, programación y seguimiento de estos. Así concebido el PI pretende incidir positivamente no solo en la situación de las trabajadoras, sino en toda la plantilla, dado que el objetivo final es la igualdad real. De los PI se ha dicho que "representan herramientas sumamente útiles para corregir la desigualdad entre mujeres y hombres". Y es que, partiendo de un diagnóstico de la concreta situación de la empresa los planes se definen por articular un conjunto de medidas tendentes a corregir las carencias evidenciadas en la fase previa de diagnóstico, fijando los concretos objetivos a alcanzar, las acciones comprometidas para conseguirlos, los recursos dotados a tal fin, los plazos y las personas responsables de llevar a cabo tal tarea.

En definitiva, sea como fuere, y para no alargar más de lo estrictamente necesario estas líneas introductorias, lo cierto es que en esta última década trascurrida desde la aprobación de la LOI, España ha pasado de tener una regulación muy escasa en materia de igualdad a tener una de las más avanzadas y completas y la igualdad ha pasado de ser un tema prácticamente desconocido en la negociación colectiva a ser en materia de obligado tratamiento ex art. 85.1 ET. Ahora bien, esta última década ha sido, además, trágica en términos de crisis económica y de empleo y ello ha tenido consecuencias directas en el desarrollo y proliferación de los PI. No siendo el principal problema que los PI presentan, si es cierto que hay que reconocer la incidencia directa de la crisis en ellos y su impac-

\footnotetext{
${ }^{8}$ También en el III Acuerdo para el Empleo y la Negociación Colectiva (2015-2017) también se preveía un Capítulo III rubricado "Impulsar el empleo de calidad y con derechos" entre cuyos objetivos fundamentales de los convenios colectivos se incluía el cumplimiento del principio de igualdad entre mujeres y hombres. En el punto 6 de este capítulo se abordaba específicamente la igualdad de trato y oportunidades y se señalaba "la necesidad de promover la igualdad de trato y oportunidades en el empleo para responder, tanto a la diversidad del mercado de trabajo, como ara maximizar el impacto y los beneficios que tienen en las empresas la presencia de plantillas heterogéneas en términos de sexo, edad, orientación sexual, nacionalidad, origen racial o étnico, discapacidad, convicciones religiosas, .... Y, de forma más concreta, se indicaba que la negociación colectiva "nos permite a las organizaciones sindicales y empresariales, contribuir a la igualdad de trato y de oportunidades en las empresas respondiendo a la diversidad actual de las plantillas y de la sociedad y consiguiendo aprovechar el potencial humano, social y económico que supone esta diversidad". A continuación se realizaban una serie de recomendaciones generales a tener en cuenta en los convenios colectivos ente los que estaban: avanzar en el desarrollo de criterio orientadores de medidas que fomenten la igualdad de oportunidades con pleno ejercicio de la autonomía colectiva; promover cláusulas antidiscriminatorias que permitan adecuar el contenido de los convenios a la normativa vigente y contribuir al establecimiento de un marco equitativo para el desarrollo de las condiciones de trabajo; y promover la igualdad de trato y de oportunidades por cualquier circunstancias personal y/o social, abordando medidas u orientaciones en relación con la igualdad entre mujeres y hombres, y trabajadores migrantes, trabajadores con discapacidad. Pero, también, de otras más específicas entre las que se encontraban el incluir criterios sobre la incorporación de cláusulas de acción positiva, el establecimiento de sistemas de selección, clasificación, promoción y formación, la eliminación de denominaciones sexistas en la clasificación profesional, la subsanación de diferencias retributivas o la incorporación de medidas o criterios que mejoren el acceso al empleo, la promoción y la formación, prestando especial atención a la contratación de mujeres en aquellos sectores en los que estén subrepresentadas, entre otros.

${ }^{9}$ ARAGÓN GÓMEZ, CRISTINA Y NIETO ROJAS, PATRICIA: “El impulso a los planes de igualdad en el RD Ley 6/2019”, en DE LA PUEBLA PINILLA, ANA (Dir.): Tiempo de reformas, Tirant lo Blanch, 2019, p. 323.
} 
to relativo. Ni siquiera pensamos haya de considerarse como uno de sus enemigos sino más bien como un elemento contextual -terreno más o menos fértil- que determina la receptividad o no ante temas tan sensibles social y jurídicamente hablando como el que nos ocupa. Pero lo que es innegable es que la LOI entró en vigor casi forma simultánea con el desencadenamiento de la última gran crisis económica y global. Ante tal evidencia, conviene recordar que los convenios colectivos responden siempre a un equilibrio de fuerzas y, en momentos de crisis como los vividos, es frecuente constatar cómo se anteponen muchas otras reivindicaciones que relegan a un segundo plano las relativas a la igualdad. Dicho en otras palabras, la igualdad es concebida como un tema menor dentro de las empresas, como "algo relativamente superfluo dado lo que está cayendo ${ }^{10 "}$, afirmaron algunos. Y conviene tener presente que al tratarse de un derecho fundamental ${ }^{11}$, su desarrollo no puede supeditarse ni a las condiciones económicas de una empresa en particular ni a las de la economía en general ${ }^{12}$. Y, en este sentido, "la crisis ha tenido un fuerte impacto en la destrucción de empleo y en el propio desarrollo de los Planes de Igualdad, por un falso entendimiento del derecho a la igualdad como un derecho social y económico, cuando posee un carácter esencial para la verificación de un estado democrático de derecho ${ }^{13}$ ". 0 lo que es lo mismo, las políticas de igualdad no deben verse afectadas por la crisis porque el derecho fundamental a la igualdad efectiva consagrada en nuestra Carta Magna no está sujeto a las condiciones económicas de los estados o, mejor dicho, no debería estarlo.

En consecuencia, los resultados de la LOI han sido discretos y, ante tal evidencia, se aprueba el Real Decreto-Ley 6/2019, de 1 de marzo, de medidas urgentes para la garantía de la igualdad de trato y de oportunidades entre mujeres y hombres en el empleo y la ocupación (en adelante, RDL 6/2019) que busca, en general, "dar a la sociedad un marco jurídico que permita dar un paso más hacia la plena igualdad" (E.M. del RDL 6/2019) y, para ello, además de su medida estrella, incorpora otras que, pese a haber pasado más desapercibidas, tienen una importancia nada desdeñable. Cuando decimos medida estrella nos referimos la extensión de "exigencia de redacción de los planes de igualdad a empresas de cincuenta o más trabajadores, creando la obligación de inscribir los mismos en el registro

\footnotetext{
${ }^{10}$ MAZA CASO, ESTER: "Planes de igualdad en tiempos de crisis: consideraciones prácticas", AEDIPE: Revista de la Asociación Española de Dirección de Personal, no 11, 2012, p. 44.

${ }^{11}$ La igualdad de trato y de oportunidades entre mujeres y hombres es un derecho básico de las personas trabajadoras y debe suponer la ausencia de toda discriminación, directa o indirecta, por razón de sexo, y, especialmente, las derivadas de la maternidad, la asunción de obligaciones familiares y el estado civil. Pero supone, asimismo, su equiparación en el ejercicio de los derechos y en el cumplimiento de las obligaciones de tal forma que existan las condiciones necesarias para que su igualdad sea efectiva en el empleo y la ocupación. Y, precisamente por ello, son contrarias al derecho a la igualdad de trato y de oportunidades entre mujeres y hombres -tanto en tiempos de crisis como en tiempos de expansión- las discriminaciones directas e indirectas, el acoso sexual y el acoso por razón de sexo, la discriminación por el embarazo, la maternidad, la asunción de obligaciones familiares o el ejercicio de los derechos de corresponsabilidad de la vida personal, familiar y laboral, las represalias como consecuencia de las denuncias contra actos discriminatorios y los actos y cláusulas de los negocios jurídicos que constituyan o causen discriminación por razón de sexo.

${ }^{12}$ BODELON GONZALEZ, ENCARNA (DIR.): El impacto de los planes de igualdad en las empresas, Universidad Autónoma de Barcelona, Grupo de Investigación Antígona de la UAB, NIP0:685-14-031-6, Exp. 4/09, pp. 60 y ss., disponible en http:// www.inmujer.gob.es/areasTematicas/estudios/estudioslinea2014/docs/El_impacto_planes_Igualdad_empresas.pdf

${ }^{13}$ GARRIDO JIMÉNEZ, LORENA: "Los planes de igualdad en las empresas y su desarrollo en momentos de crisis", http://vlex.com/vid/planes-igualdad-empresas-momentos-crisis-339347262, pp. 403-404 de la versión electrónica.
} 
que se desarrollara reglamentariamente", pero consideraremos otras como el obligatorio consenso de un diagnóstico que, ahora, ha de tener unos contenidos específicos; la mayor concreción de las materias que, obligatoriamente, ha de abordarse en ellos; o la obligatoriedad de su registro. Todos ellos contenidos que generaban dudas e interpretaciones diversas que, ahora y por fin, van aclarándose y proporcionando una suerte de "madurez serena" a los PI que esperamos tengan los efectos deseados.

\section{Los enemigos de los planes de igualdad}

Hace seis años ya se alertaba sobre el hecho cierto de que "la efectividad de los PI puede verse mermada tanto por un diagnóstico incorrecto, como por la ineficacia de la comisión de seguimiento, pero, sobre todo, por negociar de forma exclusiva o casi mayoritariamente materias tales como los derechos de conciliación de la vida personal, laboral y familiar, el protocolo antiacoso y las medidas de violencia de género ${ }^{14 "}$. Y ello porque lo negativo, lo realmente contraproducente en este sentido, no es que no se negocie el PI, sino el hecho de que, negociándose, diste mucho de ser el instrumento jurídico más relevante en la consecución de la igualdad real de oportunidades entre mujeres y hombres en la empresa en que la LOI pretendía convertirlo ${ }^{15}$. Lo cierto es que, seis años después, los mismos enemigos acechan la efectividad real de los PI, a saber, un diagnóstico incorrecto (2.1.), una comisión de seguimiento ineficaz (2.2.) y un contenido inapropiado para el fin perseguido (2.3.) o, lo que es lo mismo, no negociar auténticas materias pro igualdad mujeres y hombres. Analicémoslos detenidamente.

\subsection{La importancia determinante del diagnóstico y los problemas derivados de un diagnós- tico incorrecto}

Considerado como el análisis detallado, preciso y riguroso de la situación sobre la igualdad de oportunidades entre mujeres y hombres dentro de la empresa, el diagnóstico del PI es determinante en aras de su efectividad real, es la clave de su éxito, su clave de bóveda. Y ello porque "aporta una base sólida y documentada sobre la que construir la arquitectura del plan de igualdad y conseguir una verdadera política de transversalización del género en el ámbito empresarial ${ }^{16 ”}$. No debe considerarse, por tanto, un simple trámite porque de realizarse un inadecuado diagnóstico de la realidad -ya sea por incompleto,

\footnotetext{
${ }^{14}$ GRAU PINEDA, CARMEN: "Los planes de igualdad como ¿nueva? técnica para la consecución de la igualdad en las empresas", en VVAA: Estado de Derecho y discriminación por razón de género, orientación e identidad sexual, Thomson Reuters Aranzadi y Universidad de Las Palmas de Gran Canaria, 2014, pp. 263-286.

${ }^{15}$ FABREGAT MONFORT, GEMMA: "Los riesgos en la negociación colectiva e implantación de los planes de igualdad ", en www.ccoo.es/comunes/temp/recursos/1/pub62484.pdf. También, FABREGAT MONFORT, GEMMA: "Planes de igualdad", en VVAA: Observatorio de la negociación colectiva. La negociación en materia de planes de igualdad: estudio analítico, CINCA ediciones y CCOO, 2013.

${ }^{16}$ Boletín Igualdad en la Empresa: “Los planes de igualdad. Diagnóstico”, Ministerio de la Presidencia, Relaciones con las Cortes e Igualdad, no 35, julio 2016, p. 4.
} 
deficiente o irreal-sobre la que va a aplicarse el PI puede dejar sin efecto todas las buenas intenciones de los negociadores ${ }^{17}$.

Con carácter general, el objetivo del diagnóstico es identificar la situación en la que se encuentra la empresa en relación con la igualdad de oportunidades entre mujeres y hombres, estudiando de forma detallada la gestión interna, al objeto de detectar áreas de mejora y diseñar una intervención contraria a la discriminación de género mediante la aprobación del PI. Con carácter más específico, el PI pretende dar a conocer las característica descriptivas de la empresa, hacer visible la situación de partida de la plantilla para detectar situaciones de desigualdad, de segregación horizontal y vertical, detectar trato discriminatorio en las prácticas de gestión de recursos humanos o conocer las percepciones y expectativas de las personas trabajadoras, entre otras, y que pueden recorrer todo el abanico de las condiciones laborales, tales como el acceso al empleo, la promoción, la formación, las retribuciones, la conciliación, las medidas de protección a la maternidad, el acoso sexual y por razón de sexo, así como las regulaciones referentes al término de la relación laboral.

Queda claro el propósito del diagnóstico, pero surgen dudas razonables sobre aspectos tales como quién debe realizarlo, cómo o si ha de consensuarse entre las partes negociadoras ${ }^{18}$. Hasta fechas recientes era unánime considerar -en la línea predeterminada por la LOI y atendiendo a su "razón de ser o finalidad", esto es, llevando a cabo una interpretación teológica o finalista de la citada norma ante su silencio respecto de este aspecto concretoque el diagnóstico se debería consensuar entre las partes, pero la falta de acuerdo en el diagnóstico no invalidaba la obligación de negociar el PI. Obviamente, si lo que se persigue -el fin último- es que las partes se sienten a negociar las medidas conformadoras del plan es preciso haber consensuado, previamente, los indicadores sobre la desigualdad existente que pretende erradicarse con las medidas que se adoptan. Es por ello por lo que, aun no siendo obligatorio, se consideraba fundamental el consenso de las partes al respecto, esto es, la aceptación tanto por el empresariado como por la representación de las personas trabajadoras del diagnóstico en el sentido de ser un reflejo fiel de la realidad de la empresa, "sin trampa ni cartón", sin maquillajes o retoques estéticos que induzcan a engaño.

A solucionar este dislate ha contribuido el RDL 6/2019 que ha venido a modificar la regulación del diagnóstico como paso previo y determinante del PI y que, como se ha adelantado, "va a suponer un cambio más allá del propio diagnóstico afectando sustancialmente al Plan de Igualdad ${ }^{19}$ ". Y es que a eso se refiere precisamente el actual art. 46.2 LOI, tras la modificación operada por el RDL antedicho, reforzando en dos momentos distintos del precepto la necesidad de que efectivamente el diagnóstico se consensue con los

${ }^{17}$ FABREGAT MONFORT, GEMMA: "La negociación colectiva de los planes de igualdad, algunas reflexiones a propósito de su eficacia", en el Boletín Igualdad en la Empresa: "Negociación colectiva y registro de planes de igualdad", Ministerio de loa Presidencia, Relaciones con las Cortes e Igualdad, no 48, septiembre 2018, p. 19.

${ }^{18}$ La Audiencia Nacional ha considerado, recientemente, nulo el plan de igualdad decidido unilateralmente por la empresa por ser éstos una manifestación propia de la negociación colectiva, que deben negociarse con los representantes de los trabajadores, sin que quepa su aprobación unilateral por la empresa (FJ 5 de la SAN 4583/2019)

${ }^{19}$ FABREGAT MONFORT, GEMMA: "La obligada negociación del diagnóstico en planes de igualdad. Un cambio sustancial”, Revista de Derecho Social, no 86, 2019, p. 208. 
representantes de las personas trabajadoras: de un lado, el hoy vigente art. 46.2 LOI dice, en su primer párrafo, que con carácter previo se elaborará un diagnóstico negociado, en su caso, con la representación legal de las personas trabajadoras que contendrá al menos las siguientes materias. De otro, se insiste en el hecho de que la elaboración del diagnóstico se realizará en el seno de la comisión negociadora del PI, para lo cual, la dirección de la empresa facilitará todos los datos e información necesaria para elaborar el mismo en relación con las materias enumeradas en el mismo apartado, así como los datos del registro regulados en el artículo 28.2 del Estatuto de los Trabajadores (en adelante, ET). A falta de un desarrollo reglamentario que no ha llegado -pese a haber transcurrido el plazo previsto para ello-, son, sin embargo, buenas noticias por lo que de disipación de dudas supone.

Y es que en aras a preservar todas las garantías para las personas trabajadoras en esta materia, lo deseable es que el PI se negocie con la representación de la plantilla y se suscriba en el ámbito del convenio colectivo que sea oportuno. Lo que no tiene sentido, y ahora se corrige por obra del RDL 6/2019, es que la obligación empresarial de entregar datos a la representación de las personas trabajadoras sea limitada, esto es, cumpla la empresa con la obligación de realizar el diagnóstico pero no pueda negociarse éste sino única y exclusivamente las medidas conformadoras del plan. Como acertadamente se ha señalado "esto plantea una mayor situación de poder fáctico en la etapa de diagnóstico, con consecuencias en las medidas y acciones a negociar ${ }^{20 "}$ porque hay estudios que ponen en evidencia una cultura empresarial que, con carácter habitual, "maquilla" los diagnósticos reales, que oculta una información que es en sí misma uno de los objetivos del PI para no verse compelidas a implementar medidas igualitarias con un impacto económico considerables, cuando la realidad es tozuda y demuestra que muchas materias podrían regular sin grandes impactos económicos o con impactos razonables.

Y, precisamente por ello, es irrelevante quien lo realice, es decir, que si bien es bastante frecuente que lo aporte la parte empresarial, el equipo directivo (fundamentalmente a través del departamento responsable de recursos humanos), no hay ningún impedimento para que pueda encargarse a un ente externo siempre que el trabajo especializado de éste se someta a debate expreso y aceptación por ambos interlocutores al inicio de la negociación. Lo realmente relevante es su verosimilitud y rigurosidad, únicas garantías de su carácter instrumental respecto de las medidas a implementar.

Repárese en el riesgo real de que un PI sea ineficaz ab initio si, por ejemplo, se pactan muchas medidas de igualdad para el desarrollo de la relación laboral y no se incide en la desigualdad de entrada, en la discriminación en el acceso porque el diagnóstico de la realidad no ha mostrado la discriminación existente en el acceso a ciertos puestos; o cuando el problema central de una empresa sea la promoción y, por no detectarlo el diagnóstico, no se incida en una problemática relevante pero no detectada. En ambos casos, es frecuente no encontrar datos en el diagnóstico ni sobre los procesos de selección del personal en la

${ }^{20}$ GARRIDO JIMÉNEZ, LORENA: "Los planes de igualdad en las empresas y su desarrollo en momentos de crisis", http://vlex.com/vid/planes-igualdad-empresas-momentos-crisis-339347262, p. 406 de la versión electrónica. 
empresa ni sobre la promoción en la empresa, dos cuestiones claramente desatendidas que ponen de manifiesto el desinterés empresarial por cuestiones basilares en la superación de la discriminación laboral. Y, sin datos reales en el diagnóstico, es imposible establecer acciones e implementar medidas en pro de la igualdad.

En definitiva, el informe de diagnóstico como documento base del trabajo para realizar el PI deberá contener un análisis serio y riguroso de la información básica de la empresa pero analizada desde una perspectiva de género, esto es, alcanzando conclusiones que a partir del análisis de datos cuantitativos y cualitativos permita hacer una descripción de la situación actual de la empresa e identificar desequilibrios entre sexos, así como proponer mejoras y ámbitos prioritarios de actuación. Un diagnóstico que responda a la realidad concreta sobre la que pretende incidir, que sea una foto fija real de la situación de la empresa, resulta fundamental para la eficacia del PI. El legislador del RD-Ley 6/2019 ha sido consciente de esto y, por eso, impone, como novedad frente a la regulación anterior, negociar el diagnóstico con los representantes de las personas trabajadoras y le fija al diagnóstico un contenido obligatorio.

2.2. El papel fundamental de la comisión de control y seguimiento del plan de igualdad en aras a garantizar el cumplimiento de lo negociado

El papel de la comisión de control y seguimiento del PI (en adelante, CCS) resulta fundamental para garantizar la eficacia de lo pactado, es decir, para garantizar la viabilidad futura del mismo ${ }^{21}$. Y ello incluye que el PI se adecúe a la realidad de la empresa conforme ésta vaya evolucionando, dado que está concebido para ser algo dinámico, cambiante, vivo como las relaciones laborales en las que va a aplicarse en pos de conseguir una igualdad real en la empresa.

Conviene tener muy presente que, en el diseño del PI, dos de los criterios fundamentales son la flexibilidad (se diseña en función de las necesidades y posibilidades de la organización) y el dinamismo (es progresivo y está sometido a cambios constantes). Y, en este sentido, el plan habrá de ser lo suficientemente flexible para permitir que se adapte a las nuevas necesidades y demandas que se detecten a través de su seguimiento, garantizando las modificaciones necesarias en cada momento. Y para ello, la labor de seguimiento, liderada y desarrollada por la CCS constituida a tal efecto ${ }^{22}$-o por la Comisión de Igualdad (CI $)^{23}$ en aquellos casos en los que se le asignen las funciones de seguimiento

${ }^{21}$ FABREGAT MONFORT, GEMMA: “La negociación colectiva de los planes de igualdad, algunas reflexiones a propósito de su eficacia", op. cit., p. 19.

${ }^{22}$ Siguiendo las pautas para la creación de la Comisión de Igualdad y cuyas funciones serán as de dinamizar y llevar el control de la puesta en marcha de las acciones, supervisar la implantación del plan y recabar información a partir de los indicadores propuestos para cada medida. Más información al respecto en Boletín Igualdad en la Empresa: "Los planes de igualdad. Diseño, implantación, seguimiento y evaluación”, Ministerio de la Presidencia, Relaciones con las Cortes e Igualdad, no 36, agosto 2016, p. 14.

${ }^{23}$ Brevemente, la Comisión de Igualdad tendrá una composición paritaria con representación tanto de la empresa, como de la plantilla a través de la representación sindical. Es aconsejable respetar la proporcionalidad de la representación sindical y es recomendable que, por la parte empresarial, las personas negociadoras tengan competencias en 
o incluso por la Comisión Paritaria (CP) cuando así se prevea- contempla la elaboración de informes de seguimiento (con una frecuencia anual) que resumirán toda la información acerca de la ejecución de las acciones, indicando su grado de ejecución, obstáculos, etc. Tanto si se opta por diferenciar comisión de igualdad y control y seguimiento atribuyendo a ambas competencias diferentes como si se data a la de igualdad de un reglamento interno de funcionamiento en el que se incluyen las funciones de seguimiento del PI, lo realmente importante es que dentro del PI se recoja la existencia de un órgano que se ocupe del control y seguimiento (supervisar su implantación) y evaluación (información sobre los indicadores).

En definitiva, una correcta implementación de PI no solo requiere una planificación previa en la que se establezcan los recursos humanos, económicos y temporales necesarios para que las medidas en el contenidas puedan llevarse a cabo, sino también la realización de análisis que estudien el impacto que la adopción del plan puede tener tanto a corto como a medio plazo. Solo si entendemos que evaluar no es ni más ni menos que constatar que las medidas propuestas se están llevando a cabo tal y como se pretendía y que están obteniendo los resultados esperados (análisis de datos y seguimiento de indicadores), entonces seremos capaces de entender la importancia de la evaluación tanto como mecanismo de ajuste como de propuestas de mejora.

En adición a lo anterior y para que el PI suponga un instrumento de tutela y garantía real, también resulta de crucial importancia que se registre y se someta a control de forma $\mathrm{y}$ fondo.

En lo que se refiere al registro ${ }^{24}$, es el RD 713/2010, de 28 de mayo, sobre registro y depósito de convenios y acuerdos colectivos de trabajo el encargado de prever el registro (art. 2 y D.A. Segunda) tanto de los PI insertos en el convenio colectivo de empresa o los acuerdos que aprueban el PI derivados de la negociación colectiva de empleo, como de los acuerdos que aprueban PI en las empresas afectadas por la negociación colectiva sectorial. También se podrá solicitar el depósito de los acuerdos que aprueben los PI de empresas que carezcan de convenio colectivo propio y no deriven de lo establecido en un convenio sectorial. Corresponde al registro de convenios y acuerdos colectivos (REGCON), adscrito a la Dirección General de Trabajo como autoridad laboral competente, la inscripción de los actos inscribibles previstos de ámbito estatal o supra-autonómico. Sin embargo, se planteaban problemas referidos a la obligatoriedad del registro que han venido a ser resueltos por el RDL 6/2019 al introducir tres nuevos apartados en el art. 46 LOI para crear un registro de PI, como parte de los registros de convenios y acuerdos colectivos de trabajo, imponiendo a las empresas la obligación de inscribir sus PI en el citado registro. Ahora bien, su constitución, características y condiciones para la inscripción y acceso al registro ha quedado pendiente de un desarrollo reglamentario que no llega -ya incumplido, 6 meses desde su entrada en vigor-.

recursos humanos y capacidad de decisión. Esta Comisión es la encargada de elaborar y negociar el PI para elevarlo a la mesa general

${ }^{24}$ Más detalles en ARAGÓN GÓMEZ, CRISTINA Y NIETO ROJAS, PATRICIA: "El impulso a los planes de igualdad en el RD Ley 6/2019”, en DE LA PUEBLA PINILLA, ANA (Dir.): Tiempo de reformas, Tirant lo Blanch, 2019, pp. 358 y ss. 
En cuanto al control de aplicación y sanción ${ }^{25}$ del incumplimiento de los PI, la Ley establece la responsabilidad de la Inspección de Trabajo y Seguridad Social (en adelante, ITSS) en el control de la correcta aplicación de los planes y programas de igualdad pactados en los convenios colectivos mediante la introducción de una serie de modificaciones en la Ley de Infracciones y Sanciones del Orden Social (en adelante, LISOS) por la disposición adicional décimo cuarta de la LOI. De un lado, se añade un nuevo apartado, el 13, al art. 7 LISOS, que pasa a considerar como infracción grave en materia de relaciones laborales "no cumplir las obligaciones que en materia de planes y medidas de igualdad establecen la Ley Orgánica 3/2007, de 22 de marzo, para la igualdad efectiva de mujeres y hombres, el Estatuto de los Trabajadores o el convenio colectivo que sea de aplicación.". Y, de otro, se modifica el art. 8 LISOS al que se añade un nuevo apartado 17, que pasa a calificar como infracción muy grave en materia de relaciones laborales "No elaborar o no aplicar el plan de igualdad, o hacerlo incumpliendo manifiestamente los términos previstos, cuando la obligación de realizar dicho plan responda a lo establecido en el apartado 2 del artículo 46 bis de esta Ley". De los datos proporcionados en los informes anuales de la ITSS se deriva que el grado de cumplimiento ha sido elevado, las sanciones pocas y poco cuantiosas y que ha habido un número relativo de requerimientos.

Pero lo realmente relevante es el sistema de control interno, esto es, la existencia en el propio PI -o en el convenio colectivo al que se anexione- de un sistema de infracciones y sanciones respecto de los incumplimientos referidos a las medidas pro igualdad en él contenidas, una suerte de "control de legalidad"26. Esto es especialmente flagrante en contenidos como los referidos al acoso, los conocidos como protocolos antiacoso respecto de los que resulta fundamental para las víctimas conocer la protección de sus derechos pero también el castigo de la persona agresora. Es evidente que "el seguimiento y la evaluación de los planes de igualdad puede enfocarse desde diferentes perspectivas y centrarse en distintos aspectos. Así, tales cuestiones podrán atender desde el contenido y estructura del propio plan en sí mismo, hasta el cumplimiento o implantación de sus diferentes estrategias y medidas ${ }^{27}$." Lo que resulta más complejo es implantar sistemas de intervención externa públicos -instituciones con competencias en la materia como el Instituto de la Mujer en este caso- o privados -auditorías- y plantea problemas de difícil solución que ya se han planteado en el pasado con ocasión de reivindicaciones similares como ocurrió, por ejemplo, respecto del propio contenido de los convenios colectivos y el papel de las direcciones generales de empleo.

\footnotetext{
${ }^{25}$ En cuanto a las sanciones consistirán tanto en la pérdida automática de ayudas, bonificaciones y, en general, de los beneficios derivados de la aplicación de los programas de empleo, con efectos desde la fecha en que se cometió la infracción, como en la exclusión automática del acceso a tales beneficios durante seis meses. No obstante, en el caso de las infracciones muy graves referidas a los supuestos de discriminación directa o indirecta por razón de sexo, las sanciones a las que se refiere el apartado anterior pueden ser sustituidas por la elaboración y aplicación de un plan de igualdad en la empresa, si así se determina por la autoridad laboral competente. No cumplir con las obligaciones que en materia de igualdad establece el Estatuto de los Trabajadores puede dar lugar también a sanciones económicas, con multas entre 626 - 6.250 euros y si la infracción es muy grave, es decir, no elaborar o no aplicar el plan de igualdad, las multas pueden oscilar entre 6.251 - 187.515 euros.

${ }^{26}$ Más detalles en ARAGÓN GÓMEZ, CRISTINA Y NIETO ROJAS, PATRICIA: "El impulso a los planes de igualdad en el RD Ley 6/2019”, en DE LA PUEBLA PINILLA, ANA (Dir.): Tiempo de reformas, Tirant lo Blanch, 2019, pp. 364 y ss.

${ }^{27}$ QUINTANILLA NAVARRO, BEATRIZ: “Evaluación y seguimiento de los planes de igualdad”, VVAA: Tutela y promoción de la plena integración de la mujer en el trabajo, Consejo Andaluz de Relaciones Laborales, 2015, p. 223
} 
Todo esto es especialmente relevante en el caso de las empresas que obtengan subvenciones para la elaboración e implantación de $\mathrm{PI}^{28} \mathrm{u}$ otro tipo de reconocimientos como, por ejemplo, el distintivo de igualdad por estar sujetas al control finalista de las mismas. En cuanto a este último, por ejemplo, resulta interesante apuntar siquiera brevemente ${ }^{29}$ que la Red Distintivo de Igualdad en las Empresas (DIE) está conformada, por el momento, por 148 empresas que, tras actividades de dinamización y puesta en común de sus iniciativas en la materia, intercambian buenas prácticas en materia de igualdad entre mujeres y hombre en el ámbito laboral. Ostentar el DIE supone un doble beneficio para las empresas: de un lado, es una marca, un label o sello de excelencia que se obtiene en convocatorias anuales que reconoce a las empresas y otras entidades que destaquen en el desarrollo de políticas de igualdad entre mujeres y hombres en el ámbito laboral mediante la implementación de planes y medidas de igualdad; $y$, de otro, al pertenecer a tal red se tiene acceso directos a distintas actividades, espacios, grupos de trabajo, etc. Y, en este marco, los controles no solo formales sino, en lo que ahora interesa destacar, materiales son mayores que en el planes de igualdad de empresas que no pertenece a la citada Red en tanto en cuanto beneficiarias de incentivos económicos públicos.

\subsection{Las consecuencias derivadas de un contenido inapropiado para alcanzar el fin perseguido}

Se ha dejado para el final este potencial enemigo de la eficacia real de los PI por tratarse del más difícil de detectar de los tres señalados dado que no interfiere en la apariencia de total legalidad que en atención a lo fijado por la LOI supone que en muchos casos los PI presenten contenidos unificados, estereotipados, calcados.

Téngase en cuenta que la LOI establece criterios orientadores para la elaboración de los PI, es decir, evita determinar un modelo uniforme de plan que encorsete a los empresas y, al contrario, les proporciona la libertad suficiente para elaborar el suyo propio sin más limitaciones, pero con diagnóstico previo. La idea inherente es, por tanto, la más absoluta de las libertades en la determinación de los contenidos en un intento por facilitar que cada uno pueda hacerse "un traje a medida" que encaje a la perfección. En este afán, la LOI permite a las personas negociadoras desde definir los contenidos, hasta señalar los sistemas de seguimiento y evaluación, pasando por la determinación de las materias, la fijación de objetivos y el establecimiento de la planificación temporal de las estrategias y prácticas.

La LOI permite que se negocien, "entre otras", las siguientes materias en los planes de igualdad: "acceso al empleo, clasificación profesional, promoción y formación, retribu-

\footnotetext{
${ }^{28} \mathrm{http}: / /$ www.igualdadenlaempresa.es/recursos/subvenciones/home.htm. La última convocatoria está contenida en la Resolución de 23 de mayo de 2019 del Instituto de la Mujer y para la Igualdad de Oportunidades (BOE de 30.05.2019).

${ }^{29}$ Tiene por objeto promover la igualdad en el ámbito de las relaciones laborales mediante el reconocimiento de aquellas empresas que destaquen por la aplicación de políticas de igualdad de trato y de oportunidades con sus plantillas. Más detalles en la web http://www.igualdadenlaempresa.es/redEmpresas/distintivo/home.htm y en, entre otras, NIETO ROJAS, P.: “Distintivos en materia de igualdad: ¿Mercadotecnia o responsabilidad social empresarial?”, revista General de Derecho del Trabajo y de la Seguridad Social, vol. 45, 2017.
} 
ciones, ordenación del tiempo de trabajo para favorecer, en términos de igualdad entre mujeres y hombres, la conciliación laboral, personal y familiar, y prevención del acoso sexual y del acoso por razón de sexo" (art. 46.2 LOI). Y, consecuencia de ello, cada PI puede abarcarlas todas ella o solo algunas, en función de sus necesidades concretas, incluso algunas otras no previstas en este listado no exhaustivo sino ejemplificativo aportado por la LOI. En este sentido es importante traer a colación la reforma llevada a cabo sobre la LOI por obra del RDL 6/2019 en el sentido de prever como materias que deberán contener los PI las siguientes:
a) Proceso de selección y contratación
b) Clasificación profesional
c) Formación
d) Promoción profesional
e) Condiciones de trabajo, incluida la auditoria salarial entre mujeres y hombres
f) Ejercicio corresponsable de los derechos de la vida personal, familiar y laboral
g) Infrarrepresentación femenina
h) Retribuciones
i) Prevención del acoso sexual y por razón de sexo

Pero, retomemos el hilo anterior. Cuando se acomete un análisis exhaustivo de los contenidos de una muestra concreta de planes de igualdad, se constata la persistencia de algunos contenidos repetitivos, habituales o recurrentes que llegan a destacar sobre los demás: conciliación, acoso y de violencia de género. Y ello llama poderosamente la atención porque tratándose de cuestiones cruciales, sin ningún género de dudas, no siempre tendrán que ver con los problemas de igualdad en la empresa, no siempre serán los temas determinantes en la empresa a favor de la igualdad real. Resulta fundamental, en este sentido, recordar que aunque cada empresa decide libremente, en el marco de la negociación del plan, las áreas de intervención -en función con los resultados del diagnóstico- resulta crucial priorizar las áreas de trabajo y establecer objetivos concretos y precisos.

\section{a) La conciliación de la vida personal, familiar y profesional}

El tema de la conciliación es un tema tan complejo que merece ser tomado en consideración con la seriedad requerida por los grandes retos ${ }^{30}$. Mientras la conciliación sea un problema para las personas trabajadoras, afectará tan negativamente a la igualdad real entre mujeres y hombres en el trabajo que devendrá en imposible. Se dice que será nece-

\footnotetext{
${ }^{30}$ Conviene recordar que, a nivel estatal, la primera ley específica que reguló este ámbito fue la Ley 39/1999 de 5 de noviembre para promover la conciliación de la vida familiar y laboral de las personas trabajadoras. Pero será la Ley Orgánica 3/2007 de 22 de marzo para la igualdad efectiva de mujeres y hombres la que, además de ampliar los derechos en esta materia, se propone como objetivos adoptar las medidas que garanticen la conciliación de la vida laboral, familiar y personal y fomentar la corresponsabilidad en la asunción de responsabilidades familiares y domésticas entre mujeres y hombres.
} 
sario esperar hasta la generación de nuestras nietas para contar con una sociedad igualitaria y corresponsable, lo que se antoja bastante descorazonador.

La conciliación de vida personal, profesional y familiar ha supuesto un gran reto social, para las administraciones y las empresas. El cambio experimentado en los roles tradicionales de mujeres y hombres y su respectiva incorporación a los espacios públicos, al mercado de trabajo y a los espacios privados de unas y otros respectivamente, ha supuesto todo un replanteamiento de las políticas públicas de cuidado y de organización del trabajo en las empresas que suponen un claro beneficio para todos.

Son ya numerosas las empresas que han adoptado, de forma inteligente a mi juicio, medidas para facilitar la conciliación de la vida personal y laboral de sus profesionales, a la vez que ofertan otro tipo de compensaciones sociales o de flexibilidad ${ }^{31}$. Ahora bien, que las empresas favorezcan la conciliación de sus plantillas, como contenido de los PI, requiere un abordaje de distintas materias desde la corresponsabilidad en el reparto de las obligaciones ${ }^{32}$ y esto es bastante complicado de entender, todavía.

Y es que el concepto de corresponsabilidad, que no es sinónimo del de conciliación, supone un paso más ya que requiere que mujeres y hombres se responsabilicen de las tareas domésticas, del cuidado y atención de hijas e hijos u otras personas dependientes y por tanto, implica superar la dicotomía público/privado, donde el espacio público está reservado para los hombres y el espacio privado/doméstico para las mujeres. Además, supone que tanto mujeres como hombres puedan dedicar su tiempo tanto al trabajo remunerado como al personal y doméstico y disponer de tiempo propio. Si, con la incorporación masiva de las mujeres al mercado de trabajo, unos y otras comparten las esferas productiva y reproductiva es indispensable implantar e impulsar medidas de conciliación que les permitan compatibilizarlas. Los PI han supuesto, en muchos casos, mejoras en la conciliación, pero no siempre han incorporado perspectivas de usos del tiempo y reparto equilibrado en las tareas de cuidado, con el peligro que ello entraña de profundizar el estereotipo de la mujer como cuidadora, si dichas medidas no van encaminadas a un nuevo modelo de ciudadanía y corresponsabilidad de los cuidados de las personas que lo requieran, además de las responsabilidades estatales necesarias para la construcción de una igualdad sustantiva. Por eso hay quienes apuntan que "lamentablemente el contenido de los Planes de Igualdad en materia de usos del tiempo y corresponsabilidad, mantienen

\footnotetext{
${ }^{31}$ Es lo que llamamos "salario emocional", un incentivo cada vez más valorado en la elección de un empleo y que se puede definir como la retribución no monetaria que ofrece la empresa al personal empleado. Entre los conceptos que incluye el salario emocional están las oportunidades de desarrollo, el bienestar psicológico y el balance de vida. Es decir, asegurar que el personal se encuentra en un entorno laboral seguro, con reconocimiento y oportunidades profesionales y que puede disfrutar de todas las facetas de la vida (trabajo, ocio, familia,...).

${ }^{32}$ El art. 14.8 de la LOI establece que serán criterios generales de actuación de los Poderes Públicos "el establecimiento de medidas que aseguren la conciliación del trabajo y de la vida personal y familiar de las mujeres y los hombres, así como el fomento de la corresponsabilidad en las labores domésticas y en la atención a la familia". Y, en este sentido, la corresponsabilidad o el reparto de responsabilidades no es una actitud de ayuda sino la distribución equilibrada en el sen del hogar familiar de las tareas domésticas, el cuidado de personas dependientes, los espacios de educación y trabajo, permitiendo a sus miembros el libre y pleno desarrollo de opciones e interés, contribuyendo a alcanzar la igualdad real y efectiva entre ambos sexos. Herramienta de apoyo no 8 “Corresponsabilidad y planes de igualdad”, como recurso disponible en www.igualdadenlaempresa.es/recursos/herramientas/docs/herramienta_Apoyo_8_corresponsabilidad_planes_igualdad.pdf
} 
a la mujer como responsable y beneficiaria mayoritaria en éstos derechos, restringiendo su concepción a una conciliación de y para las mujeres, sin una reorganización de las estructuras de cuidado, tanto domésticas como institucionales ${ }^{33 \prime \prime}$.

En consecuencia, para evitar el efecto perverso que actualmente adquieren las medidas de conciliación sobre las condiciones del empleo de las mujeres (boomerang, entre otros ${ }^{34}$ ), es del todo preciso que las medidas de conciliación se utilicen de forma corresponsable, es decir, deben emplearse por los hombres en la misma proporción que las mujeres. Y es que, se trata de medidas que pese a "formularse con un carácter neutro, la mujer es la que con mayor frecuencia ejerce el papel de cuidadora ${ }^{35 "} \mathrm{y}$, mientras esto ocurra, no podremos hablar de corresponsabilidad y promoción de un verdadero cambio en la responsabilidad masculina y el modelo de organización social porque la conciliación segura siendo una cuestión de mujeres. Es urgente, por tanto, que los PI no se limiten a incluir permisos, reducciones, blindajes y otros que solo disfrutan las mujeres trabajadoras y que se dé un paso más allá en el sentido de racionalizar los tiempos de trabajo en un nuevo modelo organizacional en el que prevalezca la productividad y el cumplimiento de objetivos frente a la cultura del presentismo. De ahí que las organizaciones empresariales deban introducir cambios en su cultura empresarial orientados hacia una conciliación corresponsable, incidiendo en el acercamiento de las medidas existentes a los hombres y garantizando así el derecho a la conciliación de mujeres y hombres.

Las empresas corresponsables desarrollan medidas que amplían y mejoran la normativa de conciliación como medio para alcanzar la corresponsabilidad. La única regulación empresarial en pro de la corresponsabilidad no puede consistir en regular las ausencias de sus trabajadoras (suspensiones, reducciones, excedencias...), sino que, más allá, debe promover medidas de flexibilidad de entrada y/o salida, de jornadas intensivas coincidiendo con las vacaciones escolares, del establecimiento de bolsas de horas que permitan acumular horas de libre disposición, fórmulas de flexibilidad espacial como el trabajo a distancia o teletrabajo, de aproximación de servicios para el cuidado de personas dependientes o menores y, por supuesto, de fomento del uso de las medidas de conciliación por parte de sus trabajadores varones ${ }^{36}$.

En definitiva, las medidas de conciliación y corresponsabilidad incluidas en los PI si bien están formuladas dentro del eje "ordenación del tiempo de trabajo y conciliación de

${ }^{33}$ GARRIDO JIMÉNEZ, LORENA: "Los planes de igualdad en las empresas y su desarrollo en momentos de crisis", http://vlex.com/vid/planes-igualdad-empresas-momentos-crisis-339347262, p. 406 de la versión electrónica.

${ }^{34}$ Por eso, es frecuente encontrar medidas incluidas en los planes de igualdad en materia de conciliación que son tan garantes para las mujeres que existe el riesgo que generen un efecto boomerang, dificultando su contratación por ser un colectivo que aparece como protegido o a propósito del cual se presume que asume -en exclusiva o de forma importante- las responsabilidades familiares.

${ }^{35}$ GUERRERO VIZUETE, ESTHER: “La conciliación entre vida laboral, personal y familiar una década después de la Ley Orgánica 3/2017”, Revista General de Derecho del Trabajo y de la Seguridad Social, no 51, 2018, págs. 294-295.

${ }^{36} \mathrm{Vid}$. in extenso, un estudio de la colección EME que lleva por título "Buenas prácticas de conciliación y corresponsabilidad en las empresas con distintivo "Igualdad en la empresa" (Red DIE). Análisis sectorial y por tamaño de empresa, Subdirección General para la Igualdad en la Empresa y la Negociación Colectiva, Instituto de la Mujer y para la Igualdad de Oportunidades, Secretaría de Estado de Servicios Social e Igualdad, Ministerio de Sanidad, Servicios Sociales e Igualdad. Disponible en http://www.igualdadenlaempresa.es/recursos/monograficos/docs/BBPP_Conciliacion_Corresponsabilidad_Red_DIE.pdf 
la vida laboral, familiar y personal", afectan a otros ejes del plan de Igualdad, mostrando de manera fehaciente como un conjunto ordenado de medidas de conciliación y corresponsabilidad acertadas y eficaces incidirá y producirá efectos positivos en todos y cada uno de los ejes del plan. De ellas se dice que son "la columna vertebral del Plan de Igual$\operatorname{dad}^{37 ”} \mathrm{y}$, por ello, las empresas desarrollan un amplio abanico de medidas em esa materia, aunque no siempre en el sentido acertado.

b) El acoso sexual y por razón de sexo

Por lo que se refiere al acoso, es cierto que es la propia LOI la que genera el efecto descrito, en el sentido de ser una materia recurrente en los PI. Pero, estando bien que se aborde, estaría mejor que resultase extensible a otros tipos de acoso, por ejemplo ${ }^{38}$.

Conviene comenzar por señalar que la $\mathrm{LOI}^{39}$ define en su artículo 7 el acoso sexual y el acoso por razón de sexo a la vez que tacha tales conductas como discriminatorias:

1. Sin perjuicio de lo establecido en el Código Penal, a los efectos de esta Ley constituye acoso sexual cualquier comportamiento, verbal o físico, de naturaleza sexual que tenga el propósito o produzca el efecto de atentar contra la dignidad de una persona, en particular cuando se crea un entorno intimidatorio, degradante u ofensivo.

2. Constituye acoso por razón de sexo cualquier comportamiento realizado en función del sexo de una persona, con el propósito o el efecto de atentar contra su dignidad y de crear un entorno intimidatorio, degradante u ofensivo

Pero es que el artículo 48 recoge expresamente que "las empresas deberán promover condiciones de trabajo que eviten el acoso sexual y el acoso por razón de sexo y arbitrar procedimientos específicos para su prevención y para dar cauce a las denuncias o reclamaciones que puedan formular quienes hayan sido objeto de este. Con esta finalidad se podrán establecer medidas que deberán negociarse con los representantes de los/as trabajadores/as, tales como la elaboración y difusión de códigos de buenas prácticas, la realización de campañas informativas o acciones de formación".

\footnotetext{
${ }^{37}$ Herramienta de apoyo no 8 "Corresponsabilidad y planes de igualdad", como recurso disponible en www.igualdadenlaempresa.es/recursos/herramientas/docs/herramienta_Apoyo_8_corresponsabilidad_planes_igualdad.pdf, pp. 9-10.

${ }^{38}$ FABREGAT MONFORT, GEMMA: “La negociación colectiva de los planes de igualdad, algunas reflexiones a propósito de su eficacia", op. cit., p. 21.

${ }^{39}$ Que traspuso la Directiva 2006/54/CE, de 5 de julio, relativa a la aplicación del principio de igualdad de oportunidades e igualdad de trato entre mujeres y hombres define, de un lado, el acoso sexual como la situación en la cual se produce cualquier comportamiento verbal, no verbal o físico no deseado, de índole sexual, con el propósito o el efecto de atentar contra la dignidad de una persona, especialmente, cuando se crea un entorno intimidatorio, hostil, degradante, humillante u ofensivo. Y, de otro lado, esta Directiva define el acoso por razón de sexo como la situación en la que se produce, un comportamiento no deseado relacionado con el sexo de una persona, con el propósito o el efecto de atentar contra la dignidad de la persona y de crear un entorno intimidatorio, hostil, degradante, humillante u ofensivo.
} 
Este artículo además añade en su apartado 3 que el acoso sexual y el acoso por razón de sexo se considerarán en todo caso discriminatorios y en su apartado 4 que el condicionamiento de un derecho o de una expectativa de derecho a la aceptación de una situación constitutiva de acoso sexual o de acoso por razón de sexo se considerará también acto de discriminación por razón de sexo

Es evidente que la forma más efectiva de evitar el acoso sexual y el acoso por razón de sexo es promoviendo unas relaciones respetuosas con todas y cada una de las personas con las que nos relacionamos por motivos profesionales. Y es que, una prevención eficaz, debe incidir tanto en las actitudes y comportamientos de las personas como en los métodos y estilos de gestión. La información, la sensibilización y la formación son también estrategias básicas para que todos asuman su responsabilidad, evitando aquellas acciones que puedan resultar ofensivas, discriminatorias o abusivas. Al mismo tiempo, es fundamental que todos sean conscientes de que, en el caso de que se produzcan, estos comportamientos no se tolerarán y que las personas que los padecen contarán, desde el primer momento, con todo el apoyo y el compromiso de la empresa, que actuará con contundencia y diligencia para resolver esta situación. Por eso, la definición, implementación y comunicación de la política empresarial a través de un protocolo es, desde esta perspectiva, un instrumento clave para prevenir estas situaciones y para garantizar efectivamente la tutela de los derechos fundamentales y la seguridad y la salud de trabajadores y trabajadoras.

Siendo cierto y verdad que los PI son, en este sentido, un instrumento muy valioso de prevención, sin embargo, varios aspectos preocupan: primero, la negación de estas situaciones, esto es, que haya sido, en general, relativamente fácil introducir este tipo de protocolos en los PI argumentando la inexistencia de casos de acoso sexual o por razón de sexo en la empresa; segundo, que la realidad muestre que, en un gran número de casos, haya reticencias para iniciar los procedimientos formales y que "se prefiere "resolver el problema" en procedimientos informales, sobre todo si los presuntos acosadores tienen cargos directivos y/o de responsabilidad en la empresa ${ }^{40 "} ; \mathrm{y}$, tercero, que el empleador considere cumplida su obligación de contar con un plan de igualdad, implantando un protocolo frente al acoso (ex art. 22 LOI).

Respecto de los dos primeros aspectos señalados, esto es la negación de estas situaciones, resulta fundamental la formación y sensibilización en la materia dirigida a toda la plantilla, pero, especialmente, a las personas encargadas de ello en la empresa, así como que se contemple apoyo a la víctimas desde la empresa. Respecto del último de los aspectos apuntados, que el empleador considere cumplida su obligación de contar con un plan de igualdad, implantando un protocolo frente al acoso, conviene enfatizar en el hecho de que se trata de dos obligaciones legales distintas a las que se les puede dar cumplimiento en el mismo plan, obviamente, pero que cumplir solo con lo segundo no supone haber

\footnotetext{
${ }^{40}$ BODELÓN GONZÁLEZ, ENCARNA (DIR.): El impacto de los planes de igualdad en las empresas, Universidad Autónoma de Barcelona, Grupo de Investigación Antígona de la UAB, NIPO:685-14-031-6, Exp. 4/09, pp. 60 y ss., disponible en http://www.inmujer.gob.es/areasTematicas/estudios/estudioslinea2014/docs/El_impacto_planes_Igualdad_empresas. pdf, p. 140.
} 
cumplido con lo primero. Lo contrario es, como se ha dicho gráficamente, confundir "el todo con la parte ${ }^{41 "}$.

c) Las víctimas de la violencia de género

En cuanto a la situación de las trabajadoras víctimas de violencia de género, ocurre algo similar a lo expuesto con ocasión del acoso. Y es que vuelve a ser este un tema reiteradamente abordado en los PI y lo cierto es que sorprende.

Y es que si bien se valora positivamente la introducción en los PI de medidas para las víctimas de esta violencia en la línea predeterminada por la Ley Orgánica 1/2004, de Medidas de Protección Integral contra la Violencia de Género ${ }^{42}$ (en adelante, LO 1/2004), no obstante, no se va más allá. Y es que en la mayoría de las ocasiones se recogen solo las medidas que reconoce el Cap. II LO 1/2004 -reducción de jornada, reordenación del tiempo de trabajo, cambio de centro o movilidad geográfica, suspensión del contrato, básicamente-, sin grandes avances.

Esto no es per se negativo, del mismo modo y manera que no lo es que se negocie el protocolo frente al acoso en el PI. El problema se plantea "cuando el plan de igualdad contiene medidas poco concretas en el resto de temas (acceso, promoción, clasificación, retribución) por los que pasa "casi de puntillas", y sólo se centra en conciliación, protocolos frente al acoso y medidas para proteger a las víctimas de violencia de género ${ }^{43}$ ". Que este sea uno de los contenidos recurrentes de los PI sorprende, como sorprenden las cifras de violencia de género en nuestro país ${ }^{44}$, claro está. Pero de ahí a pensar que se trata de una problemática a tratar de forma preferente en todos los PI, va un trecho.

Partiendo de la premisa de que el trabajo es un pilar fundamental en la vida de las personas para su desarrollo personal y social, las mujeres trabajadoras víctimas de este tipo de violencia machista ven peligrar, precisamente por ser víctimas, sus puestos de trabajo por las necesidades especiales que su delicada situación conlleva. Así, la empresa, “(...) no puede considerarse un espacio completamente cerrado a las consecuencias de vi-

${ }^{41}$ FABREGAT MONFORT, GEMMA: "La negociación colectiva de los planes de igualdad, algunas reflexiones a propósito de su eficacia", op. cit., p. 21.

${ }^{42}$ La Ley Orgánica 1/2004, de 28 de diciembre, de Medidas de Protección Integral contra la Violencia de Género (en adelante, Ley 1/2004), en la que se establecieron, de forma pionera, medidas de protección integral con la finalidad de prevenir, sancionar y erradicar este tipo de violencia y prestar asistencia a sus víctimas. Esta Ley parte de la existencia de un modelo de relación entre hombres y mujeres forjado sobre un sistema patriarcal que ha de dar paso a otro paradigma de identidad y relación entre ambos sexos más adecuado a nuestro sistema democrático, pretende dar una respuesta global a la violencia de género que se ejerce sobre las mujeres. Es por ello por lo que se presenta como “(...) una norma omnicomprensiva de todos los ámbitos en los que puede incidir dicha violencia. Por ello abarca aspectos muy dispares, como son los preventivos, educativos, sociales, asistenciales y de atención posterior a la víctimas (...)", en SEGOVIANO ASTABURUAGA, Ma LUISA: "Incidencia de la Ley Orgánica 1/2004, de 28 de diciembre, de medidas de protección integral contra la violencia de género, en el ámbito laboral”, Información Laboral, Legislación y Convenios Colectivos, no 14, 2005, p. LN-4.

${ }^{43}$ FABREGAT MONFORT, GEMMA: "La negociación colectiva de los planes de igualdad, algunas reflexiones a propósito de su eficacia", op. cit., p. 22.

${ }^{44} 12$ en lo que va de año y solo llevamos dos meses y 55 en 2019. Mas detalles en http://inmujer.gob.es/MujerCifras/Violencia/VictimasMOrtalesVG.html 
cisitudes que influyen tan profundamente en la vida de sus trabajadores como la violencia de género (... $)^{45 " . ~ A ~ n a d i e ~ e s c a p a ~ q u e ~ l o s ~ p r o b l e m a s ~ d e r i v a d o s ~ d e ~ p a d e c e r ~ e s t e ~ t i p o ~ d e ~ v i o-~}$ lencia afectan, normalmente, al rendimiento de las trabajadoras de tal modo que requieren de una protección distinta de la que ofrecen las leyes laborales a las trabajadoras que no son víctimas de la violencia de género, sin que, por otro lado, ello suponga una carga excesiva para los empresarios. Pero es que, además, si a ello se une que el trabajo es un instrumento fundamental para la emancipación económica de la mujer y medio principal para aumentar su autonomía personal y social, resulta que la respuesta que se dé por parte de los poderes públicos en este sentido va a resultar crucial para romper el "círculo de sujeción ${ }^{46 "}$ de la mujer al hombre que se halla en el fondo de este problema social. Se trata, en definitiva, de neutralizar esa "fuerza centrípeta" que atrae fatalmente a la mujer que la sufre al ámbito de dominación masculina, revirtiendo la "espiral desprofesionalizadora" de la violencia a través de todas las medidas posibles ${ }^{47}$. Y, en este sentido, la intervención legislativa era del todo necesaria. La Ley 1/2004, que realizó un muy notable esfuerzo de regulación en este sentido, establece entre sus principios rectores (art. 2) la garantía de los derechos en el ámbito laboral para, así, conciliar los requerimientos de la relación laboral con las circunstancias de aquellas trabajadoras que sufran violencia de género, así como sus derechos económicos con el fin de facilitar su integración social ${ }^{48}$. Como orientación general, la citada ley vino a apuntar dos líneas de actuación relacionadas con lo que desde entonces se rubrica con la denominación de "derechos sociolaborales" de las víctimas de este tipo de violencia ${ }^{49}$.

Lo que ocurre, y es lo que dificulta la efectividad de los PI que, en esta materia, si bien la LOI ha recogido el testigo de su predecesora la Ley $1 / 2004$, lo que no estaba en su impronta es que PI entero contenga medidas tan etéreas y volubles, meras declaraciones de principios o generalidades en lo verdaderamente necesario para alcanzar la igualdad real entre unas y otros en materias tan importantes como el acceso, la clasificación, la retribución, la promoción o la formación; y, sin embargo, en las cuestiones referidas al acoso o la violencia, marginales per se, se ahonde y profundice hasta límites insospechados. Para muestra un botón: son minoría los PI que establecen mejoras, menos aun los que establecen ayudas económicas concretas (préstamos, anticipos, etc.) y casi ninguno establece medios de prueba diferentes a la orden de protección y/o sentencia -cuando diversas leyes autonómicas contra la violencia de genero así lo han previsto-.

\footnotetext{
${ }^{45}$ FERNÁNDEZ LÓPEZ, Ma FERNANDA: La dimensión laboral de la violencia de género, Bomarzo, 2005, p. 9.

${ }^{46}$ Ídem, p. 10.

${ }^{47}$ Ambas expresiones en CABEZA PEREIRO, JAIME: "El concepto y rasgos de la violencia de género. Particularidades desde el Derecho del Trabajo", en VVAA: Violencia de género y Derecho del Trabajo, La Ley, 2012, p. 97. Para el mismo autor, “(...) la violencia de género ha sido una pulsión de las sociedades tradicionales basada en la supremacía del varón, de acuerdo con los patrones socioculturales y socioeconómicos de comportamiento predominantes (...), p. 89.

${ }^{48}$ Más detalles sobre los derechos sociolaborales de las víctimas de violencia de genero impulsados por la Ley Orgánica $1 / 2004$ y, más concretamente, por la suspensión del contrato de la trabajadora víctima de este tipo de violencia en GRAU PINEDA, CARMEN: "Derechos sociolaborales de las víctimas de violencia de género: estudio concreto de la suspensión del contrato de trabajo", Revista Internacional y Comparada de Relaciones Laborales y Derecho del empleo, vol. 1, no 2, 2013.

${ }^{49}$ QUINTANILLA NAVARRO, BEATRIZ: “Violencia de género y derechos sociolaborales: La LO 1/2004, de 28 de diciembre, de medidas de protección integral contra la violencia de Género”, Temas Laborales, no 80, 2005, p. 31.
} 
Sin intención de ser reiterativas, repárese en la importancia que tiene en estos temas tan socialmente sensibles el diagnóstico, herramienta fundamental para detectar situaciones de violencia de genero tanto dentro como fuera de la empresa y articular medidas preventivas y/o reparadoras en pos de la consecución del objetivo perseguido: la igualdad en la empresa.

\section{Breve epílogo}

Que los PI pueden hacer mucho más de lo que han hecho por el momento se antoja una afirmación ingenua por obvia. Y es que siendo cierto y verdad que debe valorarse muy positivamente tanto que la LOI marcara un punto de inflexión en esta materia como que la elaboración e implementación de estos planes tenga lugar en el marco de la negociación colectiva y no en otro; también lo es que el recurso a la criticable técnica del "corta y pega" -como ya se denunciara con ocasión de los planes de prevención de riesgos laboralesestá poniendo en evidencia la frecuencia con la que se negocian PI ineficaces ab initio y cuyo único objetivo es el de cumplir con una obligación legal meramente documental.

Con carácter general, nadie cuestiona el poder de la negociación colectiva como instrumento idóneo para erradicar la discriminación en el mercado laboral y, en concreto, para prevenir las situaciones de desigualdad en las empresas y actuar frente a las mismas. Pero que, como se ha manifestado acertadamente ${ }^{50}$, los negociadores desaprovechen ese mandato para incorporar cláusulas meramente declarativas o enunciativas del principio jurídico de igualdad y no discriminación merece, como mínimo, un reproche jurídico y, como máximo, las sanciones oportunas.

Tampoco nos parece acertado, continuar situando el epicentro de la igualdad en el desarrollo de la regulación estatutaria de las ausencias o en la equiparación de la conciliación con la gestión y ordenación del tiempo de trabajo de las trabajadoras. Ha pasado ya un tiempo prudencial -más de una década- para que el relevamiento de las exigencias se entienda como fruto de la "evolución natural de las cosas". No podemos permanecer por más tiempo en esta situación de conformismo con lo ya logrado y es urgente seguir avanzando, paso o paso, pero hacia delante. El contenido de los textos convencionales es aún insuficiente y no se aprovechan las constantes llamadas de la normativa legal a la autonomía colectiva. Hay avances, eso hay que reconocerlo, pero lo cierto es que los resultados -cualitativa y/o cuantitativamente hablando- no son todo lo positivos que se podría desear cuando se aborda la lectura y análisis de textos convencionales y PI.

Y, en este sentido, la reforma operada por el RDL 6/2019, de 1 de marzo, de medidas urgentes para garantía de igualdad de trato y de oportunidades entre mujeres y hombres en el empleo y la ocupación ha venido a introducir importantes novedades en el régimen jurídico de los PI tratando de corregir las disfunciones que se habían ido poniendo de

\footnotetext{
${ }^{50}$ MENÉNDEZ CALVO, REMEDIOS: “Impacto laboral de la implementación de planes y políticas de igualdad en las empresas", op cit., p. 174.
} 
manifiesto a lo largo de estos 13 años ya de vigencia de la LOI. Sin embargo, en nuestra opinión, ha errado el tiro al centrar el objetivo en extender subjetivamente la obligación legal de contar con un PI, transitando de un modelo en el que solo estaban obligadas las empresas con más de 250 trabajadores a otro en lo que lo estén, progresivamente, las de más de $50^{51}$. Reconocemos que se trata de un intento, loable pero ingenuo, máxime cuando la realidad del tejido empresarial en España -según datos del DICE (INE) ${ }^{52}$ - es que en 2018, solo un $0.17 \%$ de empresas, sobre el total de las activas, contaba con 200 o más trabajadores. El grueso de empresas a las que imponer esta obligación legal está en las PYMES que representan casi el 99\% de nuestro tejido empresarial. Seguir pensando que este tipo de obligación legal es imponer una carga muy pesada de soportar para las empresas es perpetuar la idea de que el derecho fundamental a la igualdad y no discriminación es una carga y, lejos de normalizar/interiorizar contenidos referidos a la promoción de la igualdad como contenidos negociales, supone perseverar en la línea de considerarlos un "lujo" solo posible en épocas económicas de expansión.

Es del todo preciso que esta obligación legal se extienda a todas las empresas y que, como ya se ha apuntado acertadamente, se acepte la "propuesta de lege ferenda (...) de que se debería reformar el régimen jurídico regulador de los Planes de Igualdad con la finalidad de que estos fueran preceptivos para todas la empresa de nuestra país ${ }^{53 " .}$ Cierto es que ello exigirá coetáneamente de "un mayor apoyo técnico y promocional de la legislación y del poder público para favorecer su efectiva implantación negociada en las Pymes $^{54 ",}$ pero es la única forma -a nuestro entender- de generalizar tanto en la forma como en el fondo esta obligación legal cuyo propósito último es el de avanzar en la igualdad real en las empresas. Pero también lo es que pueda llevarse a cabo una evaluación de los PI que se están aprobando en las empresas en pos del objetivo a cumplir y que sea posible alcanzar conclusiones al respecto que ayuden a seguir en el camino de la igualdad y para ello es fundamental paliar los problemas que en aspectos como el registro, control y seguimiento se constatan.

Por último, no me gustaría concluir sin señalar que una de las principales dificultades para la implantación y desarrollo de los PI es la falta de implicación de la dirección de la empresa y aquí es donde más queda por hacer. La implicación de la dirección de la empresa en la implantación y/o desarrollo de un PI es esencial y, como demuestran los estudios empíricos al respecto, cuando la dirección de la empresa apuesta claramente por conseguir la igualdad efectiva a través de un PI, lo impulsa y cree en él, el proceso tiene más posibilidades de ser satisfactorio que en el caso contrario ${ }^{55}$. Concretamente, "se critica que la dirección de las empresas conciban los planes de igualdad como un asunto que deba ser responsabilidad del departamento de recursos humanos y no de los valores $\mathrm{y} / \mathrm{u}$ objetivos de la empresa, lo cual significa que realmente como empresa no se apuesta por

\footnotetext{
${ }^{51}$ Se prevé que, de forma gradual, vaya ampliándose tal obligación a las empresas de más de 150 en marzo de 2020, de más de 100 en marzo de 2021 y de más de 50 en marzo de 2022.

${ }^{52} \mathrm{https}: / /$ www.ine.es/jaxiT3/Datos.htm?t=299

${ }^{53}$ MONEREO PÉREZ, JOSÉ LUIS Y GUINDO MORALES, SARA: “Planes de igualdad”, op. cit., p. 579.

${ }^{54}$ Ídem.

${ }^{55}$ BODELÓN GONZÁLEZ, ENCARNA (DIR.): El impacto de los planes de igualdad en las empresas, op. cit., pp. 54 y ss.
} 
conseguir la igualdad dentro de la organización, sino que solamente se cumple con una obligación por ley ${ }^{56 "}$. Y, en este sentido, la formación en igualdad tanto de la dirección de la empresa como de la plantilla adquiere un papel crucial como instrumento en pos de la sensibilización entorno a la igualdad como derecho fundamental de un Estado de Derecho como el nuestro. Pero ese ya es otro tema...

\section{Bibliografía}

ALFONSO MELLADO, CARLOS LUIS (coord.): Observatorio de la negociación colectiva. La negociación colectiva en materia de planes de igualdad: estudio analítico, Cinca, 2013. ARAGÓN GÓMEZ, CRISTINA Y NIETO ROJAS, PATRICIA: "El impulso a los planes de igualdad en el RD Ley 6/2019", en DE LA PUEBLA PINILLA, ANA (Dir.): Tiempo de reformas, Tirant lo Blanch, 2019.

BODELÓN GONZÁLEZ, ENCARNA (DIR.): El impacto de los planes de igualdad en las empresas, Universidad Autónoma de Barcelona, Grupo de Investigación Antígona de la UAB, NIPO:685-14-031-6, Exp. 4/09, pp. 60 y ss., disponible en http://www.inmujer.gob.es/areasTematicas/estudios/estudioslinea2014/docs/El_impacto_planes_ Igualdad_empresas.pdf

Boletín Igualdad en la Empresa: "Los planes de igualdad. Diagnóstico", Ministerio de la Presidencia, Relaciones con las Cortes e Igualdad, no 35, julio 2016.

Boletín Igualdad en la Empresa: "Los planes de igualdad. Diseño, implantación, seguimiento y evaluación", Ministerio de la Presidencia, Relaciones con las Cortes e Igualdad, no 36 , agosto 2016 .

CABEZA PEREIRO, JAIME: "El concepto y rasgos de la violencia de género. Particularidades desde el Derecho del Trabajo", en VVAA: Violencia de género y Derecho del Trabajo, La Ley, 2012.

FABREGAT MONFORT, GEMMA: "Los riesgos en la negociación colectiva e implantación de los planes de igualdad ", en www.ccoo.es/comunes/temp/recursos/1/pub62484.pdf.

FABREGAT MONFORT, GEMMA: “Planes de igualdad”, en VVAA: Observatorio de la negociación colectiva. La negociación en materia de planes de igualdad: estudio analítico, CINCA ediciones y CCOO, 2013.

FABREGAT MONFORT, GEMMA: "La negociación colectiva de los planes de igualdad, algunas reflexiones a propósito de su eficacia", en el Boletín Igualdad en la Empresa: "Negociación colectiva y registro de planes de igualdad", Ministerio de la Presidencia, Relaciones con las Cortes e Igualdad, no 48, septiembre 2018.

FABREGAT MONFORT, GEMMA: La obligatoriedad del Plan de Igualdad tras el RDL 6/2019, de 1 de marzo, Bomarzo, 2019.

FABREGAT MONFORT, GEMMA: "La obligada negociación del diagnóstico en planes de igualdad. Un cambio sustancial”, Revista de Derecho Social, nº 86, 2019.

${ }^{56}$ Ídem, p. 61. 
FERNÁNDEZ LÓPEZ, Ma FERNANDA: La dimensión laboral de la violencia de género, Bomarzo, 2005, p. 9.

FERNÁNDEZ-PEINADO MARTÍNEZ, ALICIA Y BASTERRA HERNÁNDEZ, MIGUEL: "Principales actuaciones en materia de no discriminación por razón de sexo en las empresas con el distintivo "igualdad en la empresa". Puntos críticos y propuestas de mejora", Revista Internacional y Comparada de Relaciones Laborales y Derecho del Empleo, Vol. 7, nํ 3, 2019.

GARRIDO JIMÉNEZ, LORENA: "Los planes de igualdad en las empresas y su desarrollo en momentos de crisis", http://vlex.com/vid/planes-igualdad-empresas-momentoscrisis-339347262

GRAU PINEDA, CARMEN: “Derechos sociolaborales de las víctimas de violencia de género: estudio concreto de la suspensión del contrato de trabajo", Revista Internacional y Comparada de Relaciones Laborales y Derecho del empleo, vol. 1, no 2, 2013.

GRAU PINEDA, CARMEN: "Los planes de igualdad como ¿nueva? técnica para la consecución de la igualdad en las empresas", en VVAA: Estado de Derecho y discriminación por razón de género, orientación e identidad sexual, Thomson Reuters Aranzadi y Universidad de Las Palmas de Gran Canaria, 2014.

GUERRERO VIZUETE, ESTHER: “La conciliación entre vida laboral, personal y familiar una década después de la Ley Orgánica 3/2017", Revista General de Derecho del Trabajo y de la Seguridad Social, no 51, 2018.

Herramienta de apoyo no 8 "Corresponsabilidad y planes de igualdad", como recurso disponible en www.igualdadenlaempresa.es/recursos/herramientas/docs/herramienta_Apoyo_8_corresponsabilidad_planes_igualdad.pdf.

LÓPEZ INSUA, BELÉN DEL MAR: El principio de igualdad de género en el derecho social del trabajo, Laborum, 2017.

MAZA CASO, ESTER: "Planes de igualdad en tiempos de crisis: consideraciones prácticas", AEDIPE: Revista de la Asociación Española de Dirección de Personal, no 11, 2012, p. 44.

MENÉNDEZ CALVO, REMEDIOS: “Impacto laboral de la implementación de planes y políticas de igualdad en las empresas", Anuario de la Facultad de Derecho de la Universidad de Alcalá, IV, 2011.

MONEREO PÉREZ, JOSÉ LUIS y GUINDO MORALES, SARA: “Planes de igualdad”, en SÁNCHEZ TRIGUEROS, CARMEN (Dir.): Un decenio de jurisprudencia laboral sobre la Ley de igualdad entre mujeres y hombres, BOE, 2018.

MONEREO PEREZ, JOSÉ LUIS y LÓPEZ INSUA, BELÉN DEL MAR: “EL principio de igualdad y no discriminación por razón de género en los convenios colectivos", en RODRÍGUEZ ESCANCIANO, SUSANA y MARTÍNEZ BARROSO, Ma DE LOS REYES (Dir.): Propuestas para la igualdad de género en los procesos de negociación colectiva, Aranzadi, 2016. NIETO ROJAS, PATRICIA: "Los planes de igualdad entre la Ley y la negociación colectiva: un dialogo insuficiente”, Revista de Información Laboral, no 10, 2015.

NIETO ROJAS, PATRICIA: "Distintivos en materia de igualdad: ¿Mercadotecnia o responsabilidad social empresarial?", revista General de Derecho del Trabajo y de la Seguridad Social, vol. 45, 2017. 
NIETO ROJAS, PATRICIA: "La promoción profesional de las mujeres en el mercado de trabajo español. Propuestas para reducir la segregación horizontal y vertical”, Femeris, vol. $4, \mathrm{n}$ 으. 2 .

QUINTANILLA NAVARRO, BEATRIZ: “Violencia de género y derechos sociolaborales: La LO 1/2004, de 28 de diciembre, de medidas de protección integral contra la violencia de Género", Temas Laborales, no 80, 2005.

QUINTANILLA NAVARRO, BEATRIZ: "Evaluación y seguimiento de los planes de igualdad", VVAA: Tutela y promoción de la plena integración de la mujer en el trabajo, Consejo Andaluz de Relaciones Laborales, 2015.

ROMERO RÓDENAS, Ma․ JOSE: Planes de igualdad, Bomarzo, 2018.

SEGOVIANO ASTABURUAGA, Mํㅡㄴ LUISA: “Incidencia de la Ley Orgánica 1/2004, de 28 de diciembre, de medidas de protección integral contra la violencia de género, en el ámbito laboral", Información Laboral, Legislación y Convenios Colectivos, no 14, 2005. 